\title{
Practise of Crisis Intervention among Malaysian Counsellors
}

\author{
Nor Shafrin Ahmad, Siti Fatimah Kamal, Ahmad Amin Mohamad Sulaiman \\ Universiti Sains Malaysia \\ sham@usm.my; kamal.sitifatimah@yahoo.com; amin.sulaiman@mara.gov.my
}

\begin{abstract}
Crisis intervention is a method used to handle people in crisis. It offers immediate, short-term help toindividuals who experience distressful or traumatic event. Crisis may cause psychological breakdowns andopportunity depends on how it been intervene. Thus, counsellors must practise effective crisis intervention inhandling crisis cases. This study aims to examine the 1 . counsellor's understanding of crisis; 2. process usedby counsellors in conducting crisis interventions; 3 . model used by counsellors on handling crisisintervention. 21 counsellors' with crisis intervention experience selected as a sample by purposive sampling.A semistructured interview method used to obtain information. The findings were obtained using frequencyand content analysis through the development of themes according to the research questions. The findingssuggest majority (11 counsellors) understand that crisis is an event that has an impact on individuals. Fivecounsellors pointing out that crisis is an event or conflict that causes the individual not to function properlywhile three others further state that crisis as a sudden occurrence in life. One responding counsellorunderstands that crisis needs an immediate solution while another counsellor sees that crisis a need that canbe help through counselling session. The findings also shows that counsellors list various processes ofintervention, including; identify problems; ensure safety; give support; exploring alternatives; make plans;get a commitment; provide follow-up assistance and general counselling processes. Findings on model ofcrisis used shows that 11counsellors were uncertain on the model they used. Five counsellors stated that theyare using the module or other crisis intervention guidelines to replace the existing crisis model. Threecounsellors used the Gilliland Model and two used the Roberts Models. This study explains the grasp ofMalaysiancounsellor's on crisis, the process of crisis intervention, and model used in handling crisisintervention. This finding also clarifies that Malaysian counsellors still need more knowledge and training oncrisis interventions according to proper crisis model.
\end{abstract}

Keywords: Crisis, model of crisis intervention, counsellors.

\section{INTRODUCTION}

Crisis happens as a part of human life and is normal (Kanel, 2012). However, not all problems faced by individuals are categorised as crisis (Meijers, 2010). Crisis is a condition when normal life of a person halted or averted (Amini, 1999). Crisis victims are seen no longer continuing life as usual. Pressure in individual's life has become a factor for crisis (Greenstone \& Leviton, 2010). Among incidents contributing to crisis are accidents at home, vehicular accidents, arrested and faced trial in court, changing school or workplace, natural disaster, huge changes in life and loss of something significant in life (Greenstone \& Leviton, 2010).

Immediate handling of crisis might prevent prolonged effect. Muran (2010) states that crisis intervention happens in short time, stressing on the need of support, helping victim to stabilise and planning an acceptance strategy towards crisis faced. Kanel (2012) suggest that in helping crisis victim, counsellors have to identify the incident and victim's perception on the situation. Counsellors need to focus on thissincethe victim pressured to a state of non-functionality to which normal solutions turn ineffective. As stated by the Registered Nurses' Association of Ontario (2006)individual eventually develops stress because of inability to overcome any incident with commonly used solutions.

Without much needed intervention, emotional reactions of affected person might touch daily life performances, endanger life, and might lead to long-term psychological problems. For some individual, effect of crisis also expressed in form of isolation, such as withdrawing from family and friends and avoiding favourite activities (DeWolfe, 2000). Crisis intervention is the prime method which proves to be effective for all critical incident victims, especially victim of overwhelming stress which may lead to psychological trauma (Flannery \&Everly, 2000).

Crisis intervention aims to stabilise, reduce symptoms of crisis, and recover acute adaptation function, also to ease recovery process. Puleo and McGlothlin (2010), states that such intervention should take place during the crisis, not planned. Flannery and Everly (2000) supported the notion by stating that psychological crisis intervention should be given during the emergency, immediate, and acute.

Crisis intervention gives alternative to client to learn the skill to handle new stress while identifying, mobilising and improving self-capability of the client. This elaborated procedure explains how to act quickly, make a reasonable assessment towards crisis, conducting success intervention and become reference. An intervention considered successful when thecrisis was properly managed and not merely solving problem faced by crisis victim (Greenstone \& Leviton, 2010).

Since crisis intervention is an important measure in helping one to handle crisis in life, this article aims to discuss the practice used by the counsellors in Malaysia in handling such crisis cases.

\section{OBJECTIVES}

Three objectives or aims of this study are to examine:

1. counsellor's understanding of crisis;

2. process used by counsellors in conducting crisis interventions; 
3. model used by counsellors on handling crisis intervention.

\section{METHODOLOGY}

This research is an early survey involving a small group of counsellors, which are in-service of different occupational background in Malaysia.Samples selected through purposive sampling involving counsellors from a various governmentagencies, with real experience in handling crisis cases. 21 respondents are involved including from Civil Service Department, Higher Educational Institution counsellors, and school counsellors.

Before conducting the research, researcher asked for respondents' agreement to take part. Researcher then explains respondents' rights to withdraw from the research if they find the questions asked as disturbing or too difficult to answer. Researcher also explains the confidentiality of respondents' personal details and the data collectedstrictly used for this research only.

Semi-structured interview is used for gathering information. To collect information, a set of guideline prepared accordance to the research objective. This includes the details of information on experience in handling crisis with three other: 1 . definition of crisis as understood by the counsellors; 2 . process used by counsellors while conducting crisis intervention; 3 . model used by counsellors while handling crisis intervention

The following questions are used as a guideline for collecting data, but other relevant questions are permitted as long it enriches the data. The questions are:

1. What do you understand about crisis?

2 . What is the process you used in conducting crisis intervention?

3. What crisis model that you use to handle crisis cases?

The information from the interview later transcribed and analysed to gather frequency pattern of respondents' answers. Content analysis technique also used to gather the themes from the transcript of interview.

\section{RESULTS AND DISCUSSION}

\section{Understanding of crisis}

Crisis occurs when individual fail to handle incidents in life. However, other initiating elements were likely present making it overwhelming for the victims. The research finds that most of the respondents (11 counsellors, 52.4\%) do understand that crisis is an incident that leaves a mark on individual. Maladaptive effects are noticed on crisis victim who fails to handle incidents faced by using their usual method (Roberts, 1991). Failed to handle incidents using usual method, crisis victims later will develop noticeable maladaptive effect (Roberts, 1991).
Five other counsellors $(28.3 \%)$ states that crisis is an incident or conflict which causes a person fails to function. Dattilio and Freeman (2010) supported this by stating that crisis victimswerereported to show different functionality after involved in a crisis. Victims could not think well thus weaken social relationship with others people due to the crisis.

Crisis usually happens unforeseen. Crisis victims abruptly have to face situation which they unable to handle (Dattilo\& Freeman, 2010). This study shows that three responding counsellors $(14.3 \%)$ state that crisis is a sudden incident which happens in life. The opinion is supported by Roberts (1991) and Kanel (2012) whom also states that crisis happens when a person faces a sudden incident.

However, only one counsellor $(4.7 \%)$ understands that crisis required immediate solution. Based on principles of Psychological First Aid (PFA), the need of immediate support among crisis victims are not to solve the problems, but largely to help victim understand the crisis they are facing. This urgency might help crisis victim from becoming more negatively affected by crisis. Objective of crisis intervention considered achieved if the victim shows decrease of the crisis symptom (Greenstone \&Leviton, 2010).

Another counsellor (4.8\%) sees crisis as a need of help through the mean of counselling session. Counselling usually conducted after the crisis intervention took place. A stable victim then is given space to find solution towards the problems. Crisis counselling services can help crisis victims to return to their normal functional state. Despite that, Greenstone and Leviton (2010) suggest that effective crisis intervention could reduce the victim needs for other helping services such as counselling and psychotherapy.

Time is always limited in crisis. It is difficult for most people even with certain skills to cope and accept it without help. Thus, solution or immediate help is vital. Help and counselling service offered by counsellor is a follow up intervention towards a crisis faced by a person with a crisis case.

\section{Processed used by counsellor whileconducting a crisis intervention.}

Conducting a crisis intervention is importantwhile a crisis is ongoing. Those with skills and authority need to set up crisis intervention as soon as the incident happens. However, according to Greenstone and Leviton (2010), effective crisis intervention requires a specific process to give positive impact to the victims. Psychological First Aid (PFA) has highlighted an intervention process that can help reduce the crises faced. To be most effective, the helper needs to take special care of victim's view on the crisis (Greenstone \& Leviton, 2010).

In this study, the responding counsellors have listed out interventional process they had used. Among the listed process is identifying victim's crisis. Any immediate help without crisis-focused will not influence 
changes. Dattilio and Freeman (2010) reminds that although victim might faces many related problems, crisis intervention must focus on incident or problem leads to the crisis that interfere to victim's life.

A helperneed to build a good rapport so the victims are willing to share the problems. Greenstone and Leviton (2010) stressed that it is essential for a helper to treata crisis with care. A conduciveand therapeutic environment will provide calmness and comfort for the crisis victim. These skillsofdeliveringthe victim's need will also encourage victim to share concerns with the helper. Roberts (1991) states that sharing process occurs when there is a good rapport and trust between both parties.

However, the helpermustalwaysprioritise victim's safety beforehand (Dattilio\& Freeman, 2010). This is because victim's perception may develop into feeling of threat, which prevents victim from feelingrelief, resulting from inability to share (Fusco \& Freeman, 2010). Crisis victim also helped to identify any family members or any other individuals who they feel can help themduring the time or for later.

The respondent also listed giving support to victims as a process of crisis intervention. Other than basic needs, victims also need enough information, which is critical in crisis intervention (Kanel, 2012). Ahelpermustunderstand that comfort is not limited emotion and feelings, but also accurate information. Accurate information will enable victim to prepare themselves with expectation and perception about the crisis. Crisis victim has to be given related information on the crisis to prepare them to face any situation.

Next is to explore the alternative to loosen the crisis faced by the victim. Evaluating alternatives effectiveness must accord to the victim's ability and current situation. Meijers (2010) suggest that individual ability to solve problem is a factor in conserving mental health and stability. The helper will analyse alternative way for victims to handle problems since crisis usually hindered victims' ability to solve problems. This is because in crisis, problems occur and constantly need solving (Meijers, 2010).

After identifying alternatives, the helper will prepare plan to loosening the crisis faced by victim. Victim need to commit to the process. Although helper is responsible to actively offering help, the victim is not to be force to decide. If the victim needs other helps, the helper has to provide relevant aid such as crisis counselling service.

In other study, process of crisis intervention process claimed to be almost similar to general counselling. However, it is agreed in general that the process is differ because of the specific nature of intervention which supplies immediate yet effective help. Greenstone and Leviton (2010) even warn that is the biggest mistake to equate intervention crisis with counselling.

\section{Crisis model used in handling crisis intervention}

This study shows that eleven counsellors are still imprecise on the model used for crisis intervention. Five other counsellors state that they used module or other crisis intervention guideline to replace existing crisis model. Three others used Gilliland Model of crisis intervention while other two used the Roberts Model.

Roberts (1991) suggest that models are designed as guidelines for helpers in aiding crisis victims. As for counsellor, these models could be adopted as guidelines in handling crisis counselling session. This is because models contain steps or measures which are proven effective in helping crisis victim according to interventional need. Crisis intervention which becomes the foundation of helping efforts also produced based on models (Myer, Lewis, \& James, 2013). Without using any model, counsellors who conduct crisis counselling session are seen as lacking in basic knowledge of crisis intervention.

The models areconsidered to affluencecrisis counselling session since necessary steps are systematically structured. Kanel (2012) states that by using crisis intervention model, crisis cases can be conducted in short period of communication of 10 minutes per session or more than six sessions. There is an important part in aiding counsellors to understand the relation of various aspect of crisis intervention and helping them to achieve of the objectives, problem solving and crisis solving in specific.

A model could also improve crisis counselling session since the intervention and strategy is easier to grasp and remembered. This notion is supported by Roberts and Otten (2005) who states that the uses of crisis model use eases crisis counselling process. In this study, Malaysian counsellors are found to be lack in formal or non-formal trainingon crisis intervention, added by limited experience in conducting crisis intervention and crisis counselling, specifically. Failing to offer effective crisis intervention by counsellors could worsen the crisis faced by client or the crisis victim.

\section{CONCLUSION}

As conclusion, counsellors in Malaysia understand the meaning of crisis and have the knowledge of what cause crisis. Immediate intervention of crisis could avert negative impact to client or victim. Findings also shows that, although counsellors were unable to identify the precise crisis model, but the process guideline in handling the crisis is in line with the crisis intervention model by Roberts and Gilliland. This finding indicates 
that in the effort of helping crisis victim, Malaysian counsellors use accurate crisis intervention process. However, this study also show that although the guideline is relevant, Malaysian counsellor still need knowledge upgrading especially in crisis intervention model. Counsellors also need satisfactory trainingin application of knowledge, experience and skills in handling crisis cases.

\section{REFERENCES}

Amini, B. (1999). Crisis, Meaning and Consciousness. Paper presented at the Annual Convention of the American Psychological Association, Boston, America.

Dattilio, F. M., \& Freeman, A. (2010).Introduction. In Frank M. Dattalion\& Arthur Freeman, CognitiveBehavioral Strategies in Crisis Intervention (3rd ed., pp. 1-22). New York, London: The Guilford.

DeWolfe, D. J. (2000).Training manual for mental health and human service workers in major disasters (2nd ed.) (ADM-90-538), Washington, DC: Center for Mental Health Services. Retrieved from ERIC database. (ED459383).

Flannery, R. B., \&Everly, G. S. (2000). Crisis intervention: A review. International Journal of Emergency Mental Health, 2(2), 119-126.

Fusco, G. M., \& Freeman, A. (2010). The crisis-prone patient: The high-arousal cluster B personality disorders.In Frank M. Dattalion\& Arthur Freeman, CognitiveBehavioral Strategies in Crisis Intervention (3rd ed., pp. 122-148). New York, London: The Guilford.

Greenstone, J. L., \& Leviton, S. C. (2010).Elements of crisis intervention (3rd ed.). Belmont, CA: Cengage.

Kanel, K. (2012). A Guide to Crisis Intervention (4rd ed.) California: Cengage.

Meijers J. J. (2010). Problem solving and crisis intervention.In Frank M. Dattalion\& Arthur Freeman, CognitiveBehavioral Strategies in Crisis Intervention (3rd ed., pp. 456-475). New York, London: The Guilford.

Muran, E. (2010).Rape trauma. In Frank M. Dattalion\& Arthur Freeman, Cognitive-Behavioral Strategies in Crisis Intervention (3rd ed., pp. 476-493). New York, London: The Guilford.

Myer, R. A., Lewis, J. S., \& James, R. K. (2013).The introduction of a task model for crisis intervention.Journal of Mental Health Counseling, 35(2), 95.

Puleo, S., \&McGlothlin, J. (2010). Overview of Crisis Intervention. In Lisa R. Jackson-Cherry \& Bradley T. Erford, Crisis Intervention and Prevention (pp. 124). United States: Merrill.

Registered Nurses' Association of Ontario (2006).Crisis Intervention.(rev. suppl.). Toronto, Canada: Registered Nurses' Association of Ontario. Retrieved from Registered Nurses' Association of Ontario database.

Roberts, A.R. (1991). Contemporary Perspectives on Crisis Intervention and Prevention. New Jersey: Prentice Hall.

Roberts, A.R. \&Ottens, A.J. (2005). The seven stage crisis intervention model: A road map to goal attainment, problem solving and crisis resolution. Journal of
Brief Treatment and Crisis Intervention, 5(4), 329339. 